\title{
Malaria and Its Economic Burden among Pregnant Women in Rivers State, Nigeria
}

\author{
Ifeyinwa Chijioke-Nwauche', Omosivie Maduka ${ }^{2}$, Abimbola Awopeju' ${ }^{3}$, Ibinabo Oboro ${ }^{3}$, \\ Nsirimobu Paul4, Mark Ogoro5, Godly Otto ${ }^{6}$, Terhemen Kasso7, \\ Lucy Yaguo-Ide ${ }^{4}$, Claribel Abam ${ }^{8}$, Chijioke Nwauche ${ }^{8,9}$
}

${ }^{1}$ Department Clinical Pharmacy \& Management, University of Port Harcourt, Port Harcourt, Nigeria ${ }^{2}$ Department of Preventive and Social Medicine, University of Port Harcourt, Port Harcourt, Nigeria ${ }^{3}$ Department of Medical Microbiology, University of Port Harcourt, Port Harcourt, Nigeria ${ }^{4}$ Department of Paediatrics and Child Health, University of Port Harcourt, Port Harcourt, Nigeria

${ }^{5}$ Department of Geography \& Environmental Management, University of Port Harcourt, Port Harcourt, Nigeria

${ }^{6}$ Department of Economics, University of Port Harcourt, Port Harcourt, Nigeria

${ }^{7}$ Department of Obstetrics \& Gynaecology, University of Port Harcourt, Port Harcourt, Nigeria

${ }^{8}$ Malaria Elimination \& Phytomedicine Research, University of Port Harcourt, Port Harcourt, Nigeria

${ }^{9}$ Department of Haematology, Blood Transfusion \& Immunology, University of Port Harcourt, Port Harcourt, Nigeria

Email: ^godly.otto@uniport.edu.ng

How to cite this paper: Chijioke-Nwauche, I., Maduka, O., Awopeju, A., Oboro, I., Paul, N., Ogoro, M., Otto, G., Kasso, T., Yaguo-Ide, L., Abam, C. and Nwauche, C. (2020) Malaria and Its Economic Burden among Pregnant Women in Rivers State, Nigeria. Open Journal of Obstetrics and Gynecology, 10, 571-582.

https://doi.org/10.4236/ojog.2020.1040051

Received: February 28, 2020

Accepted: April 21, 2020

Published: April 24, 2020

Copyright () 2020 by author(s) and Scientific Research Publishing Inc. This work is licensed under the Creative Commons Attribution International License (CC BY 4.0).

http://creativecommons.org/licenses/by/4.0/ (c) (i) Open Access

\begin{abstract}
Background: Malaria remains a public health concern in sub-Saharan Africa especially in pregnant women because of the potential risk to the life of the mother and risk of transmission to the foetus. Treatment of malaria imposes a great economic burden on households, governments, and ultimately slows down the pace of economic development in these countries. Methods: This study estimates the economic burden of malaria among pregnant women in Nigeria, using a cross sectional survey, conducted in 8 public health institutions from the three senatorial districts of Rivers State. The data was collected from a sample of 1008 pregnant women visiting antenatal clinics using the open data kit (ODK) pretested questionnaires by trained personnel. Results: The results show that malaria has a direct economic burden of about N5826.21 or 16.18 United States Dollar (USD) for outpatient treatment including diagnostic tests and about N18,271 or 50.75 USD using an exchange rate of N360:1 USD, for inpatient treatment. A significant statistical association was established between malaria diagnosis and socio-economic status of participants ( $p$-value $<0.05$ ). It was also observed that the socioeconomic group most susceptible to malaria are those with monthly income of less than N60,000.00 (166 USD). The data show that the sources of funding the economic burden were the spouses of these pregnant women (69\%), own funds (21\%), National Health Insurance Scheme (7\%), relations and friends (3\%). Conclusion: Though the intangible cost could not be identified, the study has
\end{abstract}


shown that malaria imposes huge economic burden on households especially poor households. There is need for government to intensify its efforts in malaria eradication schemes. Efforts should be made to put in place a free malaria treatment policy for vulnerable groups like pregnant women. Furthermore, involvement of health systems in reducing the cost of treatment will decrease the economic burden on the households.

\section{Keywords}

Malaria, Cost, Burden, Pregnant Women

\section{Introduction}

Malaria illness as a health challenge is well acknowledged. In 2017, an estimated 219 million cases of malaria occurred across the world and $25 \%$ of the cases were in Nigeria [1]. The ailment is caused by a parasite that is transmitted by anopheles mosquitoes. According to Jimoh et al. [2], the most dominant species of anopheles mosquitoes instrumental for transferring the parasite in Nigeria are Anopheles funestus, Anopheles gambiae complex, Anopheles arabiensis and Anopheles melas. Nigeria can be grouped into three malaria epidemiological zones namely, forest, savannah and grassland. This study focused on pregnant women in Rivers State, which is in the forest zone. The forest zone covers mainly the southern states in Nigeria, including the South-west, South-east and the South-south [2] [3].

Rivers State, very rich in oil resources is located in the Niger Delta Region, the largest wetland in Africa [4]. Annual rainfall averages more than $3550 \mathrm{~mm}$ with the third largest mangrove forest in the world, where transmission of malaria is all year round [5] [6] [7]. According to the Nigeria Population Census data, Rivers State has a population size of 5,198,716 making it the sixth most populous state in the country [8]. The workforce in Rivers State consists mainly of men with many of the women being housewives, traders, with a few as public civil servants. According the National Bureau of Statistics [9], Rivers State had an unemployment rate of $41.82 \%$ in the third quarter of 2017 implying that 4 out of every 10 persons in the state were not doing anything, though the State is seemingly a major contributor to the National wealth of the country and housing all the major oil companies. Generally, cost of living in the State is high.

Malaria is particularly a challenge to pregnant women because of reduced immunity and the potential risks to the life of the mother and risks of transmission to the foetus [10]. Peripheral prevalence as high as $25 \%-32 \%$ malaria has been reported in East and Southern Africa among women attending antenatal clinics with about $38.2 \%$ placental malaria which persists even beyond the high infection season [10] [11]. Malaria in pregnancy has been implicated in low birth weight and maternal anaemia; inter-uterine growth restriction and preterm delivery [12]. In high transmission settings as obtained in Nigeria, pregnant wom- 
en especially primigravidae are susceptible to severe anaemia and vulnerable to malaria because of reduced immunity. In Nigeria, $11 \%$ of maternal deaths have been attributed to malaria and about 300,000 annual deaths of people are due to malaria related ailments [13]. Malaria transmission in the Niger Delta has been reported to be $11.2 \%$ and $12.56 \%$ in Bayelsa and Rivers States respectively [14] [15].

Malaria imposes huge economic burden to individuals, families and national economies eventually retarding the economic development of many African economies as huge developmental resources are redirected to resolving or mitigating this health challenge [16]. In addition huge man hours of work are lost leading to huge intangible cost. In 2017, an estimated 3.1 billion USD was spent on malaria eradication worldwide by governments of malaria-endemic countries and International partners [1].

Health economists, welfare economists and development scholars have in the past attempted to identify these costs using three main approaches namely;

1) Production Function approach

2) Cost of Illness approach (COI approach) and

3) Contingent Valuation Method (CVM)

Studies [17] [18] have used the production function approach to identify the economic burden of malaria but could not specifically identify the cost of treatment. Using regression analysis, Rolle and Omon observed that malaria constituted a drag on labour productivity, increased health expenditure and affects school enrolment negatively. Using the CVM some other studies have attempted to identify how much money, individuals or households are willing to sacrifice to stay free from malaria [2] [9]. Cost of illness approach has also been used in several studies. This approach estimates the treatment cost of malaria including relevant diagnostic tests in an accounting sense, using direct costs, intangible (indirect costs) and institutional cost of malaria treatment [19]. In the use of cost of illness (COI) approach as exemplified by Onuwujekwe et al.'s study of households and the health system in Enugu State, South Eastern Nigeria, the average cost of malaria treatment was identified as between $\$ 12.57$ and $\$ 23.2$ for outpatients and inpatients respectively [20].

This work attempts to identify the economic burden of malaria in pregnant women and the socio-economic group most susceptible to suffer from malaria in Rivers State. The need for a study of this nature cannot be over stretched. The outcome can serve as a reference point for health insurance agencies, development partners, governments and other agencies interested in malaria eradication.

\section{Materials and Methods}

\section{Study design}

This study is modelled after the approach used by Onwujekwe et al. [20] which is the cost of illness approach. In this approach, the effort is to identify the accounting cost to treat malaria. This cost is then defined as the economic bur- 
den of the disease. In addition to that approach, the study identified the socio-economic group most likely to suffer from malaria including the sources of finance for malaria treatment of pregnant women in Rivers State. This approach helps in making comparison of the outcome with that of the Enugu study, since both states belong to the forest epidemiological zone. Again the data available for the study was amenable to this model. The study was carried out from September-October, 2019.

\section{Study setting and Data Collection}

A sample size of 1000 per state was calculated based on a previously established $72.5 \%$ prevalence rate of malaria among pregnant women in the Niger Delta [21]. Stratified sample via equal allocation was employed to select two local government areas (LGA) each from the three senatorial zones, making a total of six local governments. Computer generated table of random numbers was used to select two heath facilities from two zones and four from the largest zone to make up the 8 clinics. Systematic sampling was used to select pregnant women from each of the selected health facilities. One thousand and eight (1008) pregnant women were surveyed using an open data kit (ODK) pretested interviewer questionnaire containing 39 questions administered by trained personnel with which the relevant information were harvested. Obtained data included information on demography, employment status of the women and their husbands, occupation, household income and costs of diagnosis and treating malaria among others. The respondents were recruited from eight antenatal clinics of different hospitals spread in the three senatorial zones of Rivers State. These include University of Port Harcourt Teaching Hospital (UPTH), Rivers State University Teaching Hospital (RSUTH), General Hospitals in Abua, Ahoada, Bori, Eleme and two primary health centres, Obio Cottage Hospital and Churchill Health Centre in Port Harcourt City Council (Figure 1). Due consent was obtained from the participants prior to the study. Obtained data were analysed using SPSS version 22 and results were presented in frequency, prose and tables. Fischer's test and Chi square were used for test of significance and a p-value of $<0.05$ was considered statistically significant.

\section{Ethical Approval}

Ethical approval for the study was obtained from The Research and Ethics Committee of University of Port Harcourt Teaching Hospital and the Hospital Management Board in charge of the hospitals in Rivers State prior to the start of the study.

\section{Results}

Out of the 1008 respondents that participated in the study, demographic data obtained showed an age range of 25 and above with about $68.2 \%$ between $26-35$ years (mean $30.56 \pm 4.93$ years), $98 \%$ of these women were married. The data further shows that $65.1 \%$ of these women were graduates of tertiary educational institutions, $34.5 \%$ had secondary school qualification, $0.3 \%$ were primary 
school leavers while $0.1 \%$ had no formal education at all. Traders/business women accounted for $287 \%$ or $28.5 \%$, self-employed women were 185 amounting to $18.4 \%$, teachers account for 134 participants or $13.3 \%$ while the unemployed were $118 \%$ or $11.7 \%$. Civil servants 90 (9.1\%), students $43(4.3 \%)$, artisans $20(2.0 \%)$, farmers $8(0.8 \%)$, professionals $12(1.2 \%)$ and others $19(1.9 \%)$ (Figure 2)

Household income obtained from the respondents is shown in Table 1 (mean 93,504.77 $\pm 188,986.23)$.

From Table 1 below, it can be seen that more than half $(54.3 \%(23.9+30.4))$ of the malaria burden was borne by those earning below N60,000 (\$166), thereby indicating that the socioeconomic group most susceptible to malaria are those with monthly income of less than N60,000.00 (166 USD). Out of the 1008 respondents, only 398 (39.5\%) were diagnosed with malaria and about $81 \%$ (322) of these had a laboratory test performed with an incurred cost between N1700 and N3900 (mean $1665.49 \pm 3865.91$ ). The malaria diagnosis was significantly associated with the socio-economic status of the study participants with p-values < 0.05 (Table 2).

Cost of treatment for one episode of malaria ranged from N3241.42 to N8411.50 averaging the sum of N5826.21. Treatment for hospitalised patients was at a cost N16,900.00 to N19,642.86 with average cost of N18,271 inclusive of intravenous drugs and sometimes blood transfusion.

The source of funding this economic burden is shown in Table 3.

Table 3 indicates that approximately $69 \%$ of the malaria treatment burden was borne by spouses of the pregnant women; about $21 \%$ of treatment was borne by the women themselves, $7.1 \%$ by the National Health Insurance Scheme (NHIS) while relations and friends accounted for about $3 \%$.

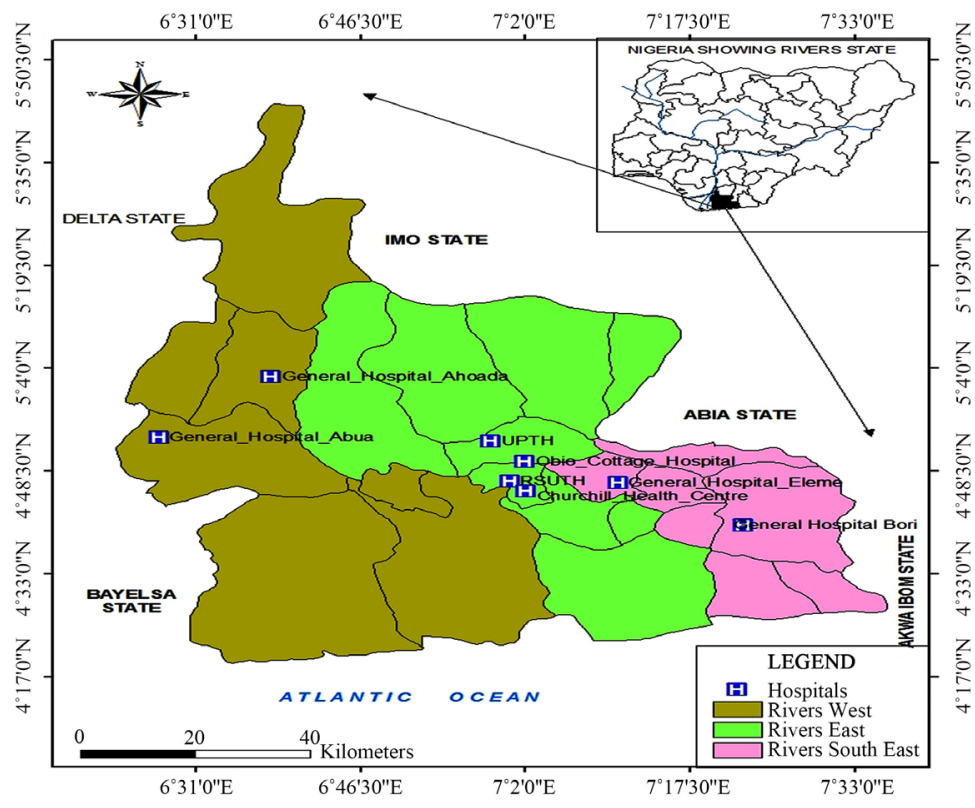

Figure 1. Rivers state showing hospital locations. 


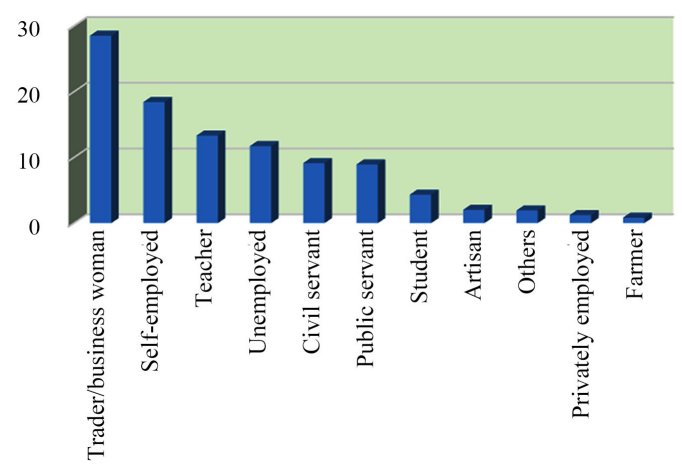

Figure 2. Distribution of respondents' occupation.

Table 1. Respondents by household income background.

\begin{tabular}{|c|c|c|c|}
\hline S/No & Family Average Income (N) & Frequency & Percent (\%) \\
\hline 1 & $<\AA 30,000$ & 226 & 23.9 \\
\hline 2 & $\mathrm{~N} 30,000-\mathrm{N} 59,999$ & 287 & 30.4 \\
\hline 3 & $\mathrm{~A} 60,000$ - N89,999 & 124 & 13.1 \\
\hline 4 & $>\mathbb{N} 90,000$ & 307 & 32.5 \\
\hline
\end{tabular}

Source: Field data.

Table 2. Diagnosis of Malaria and socio-economic status.

\begin{tabular}{ccccc}
\hline Variable & \multicolumn{2}{c}{ Malaria Diagnosis } & \multicolumn{2}{c}{ Test of Significance } \\
\hline $\begin{array}{c}\text { Family's average monthly income } \\
\text { (in Naira) }\end{array}$ & No, $\mathbf{n}(\%)$ & Yes, no (\%) & $\mathbf{X}^{2}$ & p-value \\
\hline 30,000 & $117(21.4)$ & $109(27.4)$ & & \\
$30,000-59,999$ & $157(28.8)$ & $130(32.7)$ & 12.643 & 0.005 \\
$60,000-89,999$ & $70(12.8)$ & $54(13.6)$ & & \\
$\geq 90,000$ & $202(37.0)$ & $105(26.4)$ & & \\
\hline
\end{tabular}

Source: Field data.

Table 3. Source of funding malaria burden.

\begin{tabular}{cccc}
\hline S/No & Source & Frequency & Percentage (\%) \\
\hline 1 & Personal (own funds) & 80 & 20.9 \\
2 & Spouse & 262 & 68.6 \\
3 & Relations & 7 & 1.8 \\
4 & NHIS & 27 & 7.1 \\
5 & Friends & 6 & 1.6 \\
\hline
\end{tabular}

Source: Field data.

\section{Discussion}

This study investigated the economic burden of malaria in pregnant women at- 
tending antenatal clinics in Rivers State. The results show that an average of N5, 826.21 (\$16.18) at an exchange rate of N360 per United States dollar, is spent for the treatment of one episode of malaria for outpatients while for hospitalization, the direct cost range from N16,896 to N19,642.86 average of N18,271.00 (\$50.75) which was about the minimum wage of workers in the country as at the time of the study. This burden was largely borne by the spouses of these women. By implication, for pregnant women whose spouses are not financially able to bear this burden there will be a challenge for treatment especially in acute cases that may require hospitalization. This is particularly so because the average cost of treatment of a hospitalized patient is about the monthly wage of some workers whose earn minimum wage and could be worse for the unemployed or private sector employees earning less than the stipulated minimum wage in Nigeria.

In a previous study by Jimoh et al. [2], a willingness to pay for treatment of malaria among households was $\$ 9.3$ and $\$ 9.4$ for adults and children respectively while there was the willingness to pay $\$ 11.86$ for treatment among pregnant women [22]. In the study by Onwujekwe et al., using COI approach, the direct economic burden of malaria was estimated at $\$ 12.57$ for outpatients and $\$ 23$ for inpatients. Two points explain the minor differences between these earlier studies and the outcome of the current study outcome. First is the issue of time and inflation, the second point is our location of study; Jimoh et al. [2] was in 2007 and Onwujekwe et al. [20] was in 2013. This current study is in 2019, and this explains the trend of prices. In 2007, one US dollar was equivalent to 120 Nigerian Naira, signifying a three hundred percent increase in the exchange rate. The fluctuation of the Naira and its subsequent downturn has brought a lot of economic hardship on the citizens because inflation rate in Nigeria is significantly influenced by the Naira exchange rate [23]. Secondly Rivers State is an oil rich environment and the cost of living is high unlike a national study where very poor regions of the country and low cost of living may moderate the aggregate data and lead to a general moderate cost of living.

The data also established that there is a correlation between malaria incidence and income level with the result showing that households earning less than N60,000 (\$167) had more incidence of malaria. This may be due to their low socioeconomic status hence their inability to access preventive measures thereby establishing the fact that there is a correlation between malaria incidence and poverty. This is similar to the study of Gallup and Sach [18]. Moreso, this class of people have poor sanitary habits and lifestyle which encourage easy breeding of mosquitoes and transmission of the malaria disease. According to Abdullahi, et al. [24], domestic cleanliness, personal hygiene, proper ventilation, refuse disposal and drainages have an inverse effect on the transmission of malaria. People who leave in vicinities where there is poor sanitation and do not have good malaria preventive techniques such as use of insecticide treated nets, window and door nets, and mosquito repellents stand a chance of having a higher incidence of malaria. 


\section{Conclusions}

The study using the cost of illness (COI) approach identified the economic burden of malaria among pregnant women in Rivers State using direct costs only. It has shown that the cost of malaria treatment constitutes a great financial burden on households to the tune of about N5826.21 (\$16.18) and N18,271.00 (\$50.75) for outpatients and inpatients respectively and this burden was largely borne by the spouses of these women. In addition to the treatment costs, the burden is also accrued through other means such as loss of man hours, care-giving time spent by other family members since this burden is completely borne by the families. Furthermore, the study also noted that households earning less than N60,000 or \$167 USD suffered more from the incidence of malaria.

Involvement of health systems in reducing the cost of treatment will decrease the economic burden on the households. The provision of free malaria treatment for pregnant women by the government is strongly advocated and this can be achieved through adopting the policy of Free Maternal and Child Health (FMCH) as practiced in Enugu State [20]. Additionally, government should also create more jobs to reduce the incidence of poverty and improve the socioeconomic status of the populace. Furthermore, steps should be taken to expand the coverage of the National Health Insurance Scheme (NHIS) to also capture people who are in the informal sector. Presently, people in the informal sector of the population are not registered under the National Health Insurance Scheme (NHIS) and malaria infection is not discriminatory to employment sector. Lastly in order to achieve malaria elimination, government should put in place strategies to improve overall sanitation and encourage residents to clean their surroundings and eliminate breeding grounds for mosquitoes.

A major limitation in this study is that it did not identify the intangible burden (cost) of malaria, though the study showed that inpatients could be demobilised for between 6 and 11 days (an average of 9 days). The approximate cost of these nine days demobilisation was not identified. Furthermore, we could not make a distinction between treatment cost in private and public health facilities. However, past studies have established that malaria treatment seeking behaviour is more common in the private sector and most Nigerians first consult private facilities before the public [25]. This is also obtained in other countries such as Uganda where it has been established that $59 \%$ of first consultations take place in the private sector [26]. Perhaps, this aspect of comparative costs between private and public health facilities could be taken up by a future study.

Despite the limitations, the study has been able to establish the fact that malaria places a huge economic burden on pregnant women with a greater percentage of the burden being borne by the spouses of the women. Free or subsidised malaria treatment for pregnant women is strongly advocated.

\section{Acknowledgements}

The authors appreciate the support of the field staff of the NDDC Professorial 
Chair in Malaria Elimination and Phytomedicine Research and the staff of the various institutions where the research was conducted. The cooperation of our study participants is well appreciated.

This work was supported by funds from the endowment of a Professorial Chair in Malaria Elimination and Phytomedicine Research at the University of Port Harcourt by the Niger Delta Development Commission (NDDC), Nigeria.

\section{Conflicts of Interest}

The authors declare no conflicts of interest regarding the publication of this paper.

\section{References}

[1] World Health Organization (2018)World Malaria Report.

[2] Jimoh, A., Sofola, O., Petu, A and Okorosobo, T. (2007) Quantifying the Economic Burden of Malaria in Nigeria Using the Willingness to Pay Approach. Cost Effectiveness and Resource Allocation, 5, 1428-1754.

https://www.researchgate.net/publication/6315781_Quantifying_the_economic_bur den_of_malaria_in_Nigeria_using_the_willingness_to_pay_approach https://doi.org/10.1186/1478-7547-5-6

[3] Chima, R.I., Goodman, C.A. and Mills, A. (2003) The Economic Impact of Malaria in Africa: A Critical Review of The Evidence. Health Policy, 63, 17-36. https://doi.org/10.1016/S0168-8510(02)00036-2

[4] Otto, G. (2008) The Niger Delta Crisis and Its Impact on The Nigerian Economy. The Nigerian Journal of Energy and Environmental Economics, 1, 268-282.

[5] Uluocha, N.O. and Okeke, I.C. (2004) Implications of Wetlands Degradation for Water Resources Management: Lessons from Nigeria. GeoJournal, 61, 151-154. https://doi.org/10.1007/s10708-004-2868-3

[6] Umoh, S.G. (2008) The Promise of Wetland Farming; Evidence from Nigeria. Agricultural Journal, 3, 107-112.

[7] Presidential Malaria Initiative (2011) Malaria Operational Plan NIGERIA, FY 2012.

[8] Federal Republic of Nigeria (2006) Population and Housing Census. Priority Table Volume IV, Population Distribution by Age and Sex. National Population Commission, Abuja.

[9] National Bureau of Statistics (2018) Labour Force Statistics-Vol.1: Unemployment and Underemployment Report.

[10] Desai, M., TerKuile, F.O., Nosten, F.R., McGready, R., Asamoa, K., Brabin, B. and Newman, R.D. (2007) Epidemiology and Burden of Malaria in Pregnancy. The Lancet Infectious Diseases, 7, 93-104. https://doi.org/10.1016/S1473-3099(07)70021-X

[11] Chico, R.M., Mayaud, P., Ariti, C., Mabey, D., Ronsmans, C. and Chandramohan, D. (2012) Prevalence of Malaria and Sexually Transmitted and Reproductive Tract Infections in Pregnancy in Sub-Saharan Africa: A Systematic Review. The Journal of the American Medical Association, 307, 2079-2086. https://doi.org/10.1001/jama.2012.3428

[12] Steketee, R.W., Nahlen, B.L., Parise, M.E. and Menendez, C. (2001) The Burden of Malaria in Pregnancy in Malaria-Endemic Areas. American Journal Tropical Medicine and Hygiene, 64, 28-35. https://doi.org/10.4269/ajtmh.2001.64.28 
[13] National Population Commission \& National Malaria Control Programme (NPC \& NMC) (2012) Nigeria Malaria Indicator Survey. 2010 Final Report, Federal Republic of Nigeria.

[14] Pondei, K.E., Lawani, I. and Ndiok, E. (2012) Prevalence of the Malaria Parasite in Screened Blood in a Tertiary Health Centre in the Malaria-Endemic Niger Delta Region of Nigeria; Global Advanced Research Journal of Microbiology, 1, 188-193.

[15] Ebong, O.O., Nwauche, C.A., Ogbuehi, I.H., Chijioke-Nwauche, I.N., Ezirim, C.T., Umoh, R.E., Afia, A.G. and Zara-kokpa, P. (2015) Is this Evidence of Success in Malaria Prevention and Control Measures? Greener Journal of Medical Sciences, 5, 1-10. https://doi.org/10.15580/GJMS.2015.1.051114379

[16] Federal Ministry of Health Nigeria (2005) National Malaria and Vector Control Division.

[17] Rolle, A.R and Omon, I.J. (2018) Economic Burden of Malaria: Evidence from Nigeria's Data. Amity Journal of Healthcare Management, 3, 28-39

[18] Gallup, J.L. and Sachs, J.D. (2001) The Economic Burden of Malaria. The American Journal of Tropical Medicine and Hygiene, 64, 85-96. https://doi.org/10.4269/ajtmh.2001.64.85

[19] Fonta, M.W. (2006) Valuation of Community Based Financing of Environmental Projects: A Case Study of Malaria Control in Bambalang Cameroon. Unpublished Ph.D. Thesis, University of Nigeria, Nsukka.

[20] Onwujekwe, O., Uguru, N., Etiaba, E., Chikezie, I., Uzochukwu, B. and Adjagba, A. (2013) The Economic Burden of Malaria on Households and the Health System in Enugu State Southeast Nigeria. PLoS ONE, 8, e78362. https://doi.org/10.1371/journal.pone.0078362

[21] Nzeako, S.O., Nduka, F.O. and Origie, O.A. (2013) Prevalence of Malaria in Pregnant Women Attending Ante Natal Care at University of Port Harcourt Primary Health Care Centre Aluu, Port Harcourt, Rivers State, Nigeria. International Journal of Scientific Research in Environmental Sciences, 1, 268. https://doi.org/10.12983/ijsres-2013-p268-272

[22] Onyia, V.U., Ughasoro, M.D. and Onwujekwe, O.E. (2018) The Economic Burden of Malaria in Pregnancy: A Cross Sectional Study. The Journal of Maternal-Fetal \& Neonatal Medicine, 33, 92-95. https://doi.org/10.1080/14767058.2018.1487933

[23] Nwafor, M.C. (2018) Effect of Naira Rate on Economic Growth in Nigeria. International Journal of Banking and Finance Research, 4, 58-66. https://www.iiardpub.org

[24] Abdullahi, U.B., Zainad, J.O., Rai, J.K., Gwani, M. and Gado. A.G. (2013) Effect of Some Atmospheric Variables on Malaria Prevalence in Kebbi State, Nigeria. International Journal of Environment and Bioenergy, 8, 12-21.

[25] (2012) Annual Malaria Control Programme Review: Ethiopian and Nigeria. The Carter Centre, Atlanta, GA.

[26] Uganda Bureau of Statistics (2005) National Household Survey Report. 


\section{Appendix}

Malaria parasitaemia and survey of Plasmodium species among pregnant women

This questionnaire is for research purposes to enable us assess the use of antimalarial drugs among pregnant women. Every information given in this questionnaire is confidential. Thank you for answering the questions.

Consent Yes No

Name of Facility Data Collector's Code

\section{SOCIO-DEMOGRAPHIC CHARACTERISTICS}

1) Town of Residence

2) AGE (as at last birthday):

3) MARITAL STATUS: Married ( ) Single ( ) Divorced ( ) Widowed ( )

4) EDUCATIONAL STATUS: None ( ) Primary ( ) Secondary ( ) Tertiary ( )

5) OCCUPATION: Civil servant Public servant Teacher Study ID: If no please end the interview) LGA

Trader/business woman , Farmer, Self-employed: Others (please specify)

6) What is your family's average monthly income? (to the nearest N1000)

\section{REPRODUCTIVE HISTORY}

7) Gestational Age at Booking

8) Current Gestational Age

9) Is this your first pregnancy? Yes ( ) No ( )

10) If No to above, Number of past pregnancies

11) Number of children alive

12) What year was your last pregnancy (the year)

13) Where did you deliver during your last pregnancy: Home TBA Church , Primary Health Centre Private Health

Facility General Hospital , Teaching Hospital

\section{THE SOCIO-ECONOMIC BURDEN OF MALARIA IN PREGNANCY}

14) Were you diagnosed with malaria in this pregnancy? YES/NO

15) Did you run any laboratory tests? YES/NO

16) If Yes which test did you run RDT Microscopy Don't know

17) How much did the laboratory tests costs? (to the nearest N500)

18) Were you treated for malaria in this pregnancy? YES/NO

(if No skip to question 17)

19) What treatment was given? ACT Quinine Herbs Supplements Other (pls specify)

20) What was the cost of the treatment? Free, $\leq$ N1000 $\leq$ N5000 $\leq$ N10,000 > $N 10,000$ 
21) What was the source of the funds? a) Personal b) Spouse c) Relations d) NHIS e) Friends f) Church g) Others Pls specify

22) Did you have any of the following symptoms? a) Fever b) vomiting c) chills and rigors d) Headaches e) Weakness?

23) Did the symptoms stop you from normal activity and work? YES/NO

24) If yes, how many days?

25) Did you experience any of the following? Anaemia Coma/Loss of consciousness Threatened abortion No

26) Did you have to be admitted in the hospital? YES/NO

27) If yes, how many days were you admitted for?

28) If yes, what was done while on admission? blood transfusion IV drugs or any other treatment? YES/NO

29) What was the total cost of hospitalization? (to the nearest N500)

30) How did hospitalization affect your finances? Positively/Negatively

31) Did the financial implications of hospitalization affect your relationship with spouse and kids? YES/NO

32) Do you have any other infection? YES/NO

33) If Yes to above which one? HIV ( ) Hepatitis B ( ) Typhoid fever, Others (please specify)

34) Were you given anything for prevention of malaria in pregnancy? $\mathrm{YES} / \mathrm{NO}$

35) If yes, what? ACT Fansidar Herbs Supplements Others (please specify

36) How many times have you been treated for malaria in this pregnancy?

37) What do you use to prevent malaria for your family a) window nets b) bed nets c) insecticide d) Others (please specify)

38) Did you sleep inside a bed net last night? YES/NO

39) If NO, why? a) It is uncomfortable b) It is not effective c) I do not know how to get one to use. 